\title{
Perkembangan Teknologi Komunikasi dan Sumbangannya kepada Pentadbiran British dan Masyarakat di Negeri-Negeri Selat 1902-1938
}

\author{
KOH KUAN WEI \\ Xiamen University Malaysia \\ ZUBAIDAH V. P. HAMZAH \\ AZLIZAN MAT ENH \\ Universiti Kebangsaan Malaysia
}

\begin{abstract}
ABSTRAK
Sistem komunikasi merupakan elemen penting untuk melicinkan pentadbiran selain menyediakan kemudahan perhubungan kepada masyarakat tempatan. Perkembangan ekonomi dan perubahan sistem pentadbiran British di Negeri-Negeri Selat mendorong pentadbiran British untuk memperkenalkan sistem komunikasi moden di Negeri-Negeri Selat bagi memudahkan urusan penyampaian maklumat. Kebanyakan kajian lepas dalam aspek perhubungan adalah lebih berfokus kepada perkembangan sistem pengangkutan berbanding sistem komunikasi. Sehubungan itu, objektif kajian ini adalah untuk mengenal pasti usaha-usaha yang dilakukan oleh British dalam pembangunan teknologi komunikasi di Negeri-Negeri Selat dan sumbangannya kepada pentadbiran dan penduduk tempatan. Kaedah yang digunakan untuk menjalankan kajian ini ialah kaedah kualitatif yang berasaskan metodologi sejarah dengan menjadikan bahan primer sebagai sumber analisis utama. Antara fail yang dirujuk ialah fail kolonial CO273 Colonial Office: Straits Settlements Original Correspondence dan CO275 Colonial Office: Straits Settlements Sessional Papers. Kajian mendapati bahawa pelbagai usaha telah dilakukan oleh British di Negeri-Negeri Selat untuk membangunkan sistem komunikasi yang sempurna dan efisien. Antaranya menaik taraf kemudahan telefon dan telegraf dengan menaik taraf talian-talian sedia ada. Talian-talian telefon dan telegraf juga ditambah di seluruh Negeri-Negeri Selat seterusnya memperluaskan jaringan ke Negeri-Negeri Melayu yang lain. Teknologi tanpa wayar juga diperkenalkan di Singapura dan Pulau Pinang untuk menyediakan teknologi komunikasi moden dan canggih pada era tersebut. Transformasi dalam sistem komunikasi di Negeri-Negeri Selat telah menyumbang kepada kelancaran urusan pentadbiran selain memberi manfaat dalam bidang sosial dan ekonomi.
\end{abstract}

Kata kunci: Teknologi komunikasi, pentadbiran British, Negeri-Negeri Selat, khidmat sosial, penyampaian maklumat.

\section{The Development of the Communication Technology and Its Contributions to the British Administration and Society in Straits Settlements 1902-1938}

\begin{abstract}
A communication system is an important element in facilitating the administration as well as providing communication facilities to the local community. The economic development and changes in the British administration system in the Straits Settlements led the British administration to introduce a modern communication system in the Straits Settlements to facilitate the transmission of information. Most of the previous research on communication is focusing on the development of the transportation system as compared to the communication system. Hence, the objective of this study is to identify the efforts taken by the British in developing communication technology in the Straits Settlements dan its
\end{abstract}


contributions to the administration and the local community. The methodology used for this study is qualitative. The analysis is based on the historical method by making primary sources the main source of analysis. Among the files that were referred to are colonial files $\mathrm{CO} 273$ Colonial Office: Straits Settlements Original Correspondence and $\mathrm{CO} 275$ Colonial Office: Straits Settlements Sessional Papers. This research shows that there are various efforts taken by the British in the Straits Settlements to develop a perfect and efficient communication system. This includes efforts to improvise the telephone and telegraph facilities by upgrading existing cables of communication. The telephone and telegraph cables were added all over the Straits Settlements which subsequently widened the network of communication to the other Malay States. Wireless technology was also introduced in Singapore and Penang to provide communication that is modern and sophisticated during that era. The transformation in the communication system in the Straits Settlements has contributed to the smooth running of the administration as well as bringing social and economic benefits.

Keywords: Communication technology, British administration, Straits Settlements, social service, disseminating information.

\section{PENGENALAN}

Sistem perhubungan merupakan aspek yang sangat penting dalam perkembangan ekonomi, sosial dan pentadbiran sesebuah negara. Pada tahap awal, sistem perhubungan adalah bersifat mudah, tetapi perkembangan minda dan teknologi menyebabkan sistem perhubungan menjadi lebih praktikal dari segi sifat, bentuk dan kegunaannya (Azharudin, 2001). Sistem perhubungan seperti perkhidmatan pos dan telegraf telah diperkenalkan oleh British sejak 1800-an di Tanah Melayu bagi memudahkan proses penghantaran mesej untuk kepentingan ekonomi dan pentadbiran British. Negeri-Negeri Selat telah menjadi hub komunikasi penting pentadbiran British kerana negeri-negeri tersebut merupakan kota pelabuhan utama pada era kolonial. Gabenor sebagai ketua pentadbiran kepada semua negeri koloni British di Tanah Melayu memerlukan maklumat daripada kalangan Residen dan Penasihat British yang berada di Negeri-Negeri Melayu. Setiausaha Koloni di Melaka dan Pulau Pinang juga perlu sentiasa memberi laporan kepada Gabenor tentang segala perkembangan yang berlaku di Negeri-Negeri Selat. Sehubungan itu, sistem komunikasi telah menjadi keperluan asas dalam kalangan pegawai-pegawai British kerana perkhidmatan ini membolehkan mereka untuk berhubung dengan lebih efisien (Kaur, 1985). Selain menjadi pusat pentadbiran, Singapura juga berkembang pesat sebagai kota pelabuhan utama di rantau ini sebagai tempat singgah oleh para pedagang dari seluruh rantau terutamanya dari Sumatera, Borneo, China, India dan pedagang-pedagang bebas dari Eropah. Pada masa yang sama, Pulau Pinang juga menjadi sebuah kota pelabuhan yang maju disebabkan negeri-negeri jirannya dibanjiri dengan imigran dari beberapa negara (Drabble, 2000). Dasar ekonomi British adalah untuk mengaut hasil Tanah Melayu untuk tujuan eksport bagi mendapatkan keuntungan kepada pihak pentadbiran British. Semua komoditi penting seperti bijih timah, getah dan hasil hutan akan dihantar ke Negeri-Negeri Selat untuk diperdagangkan. Dasar ekonomi British telah menyebabkan perkembangan sistem perhubungan seterusnya turut menyumbang kepada pembangunan sistem komunikasi di Negeri-Negeri Selat.

Sebelum perkembangan sistem telegraf dan telefon, penyampaian maklumat hanya melalui kaedah tradisional seperti surat terutamanya dalam urusan pentadbiran dan ekonomi. Penyampaian sesuatu maklumat memakan masa yang agak lama untuk sampai kepada penerima. Pada ketika itu, negara-negara Barat telah mempunyai teknologi komunikasi yang canggih. Oleh itu, pentadbiran British telah memperkenalkan teknologi tersebut di Negeri- 
Negeri Selat. Sistem komunikasi moden telah diperkenalkan di Negeri-Negeri Selat lebih awal daripada Negeri-Negeri Melayu yang lain iaitu awal abad ke-19 dengan pengenalan sistem telegraf di kota-kota pelabuhan untuk tujuan komunikasi bagi aktiviti ekonomi (Colonial Office: CO275/66, 1903). Singapura telah muncul sebagai sebuah pusat perdagangan utama pada pertengahan abad ke-19 dan pada masa yang sama juga sebagai hub telekomunikasi di rantau ini. Keadaan ini semakin nyata menjelang tahun 1880 -an dengan pengenalan telefon di Singapura yang menjadikannya negeri pertama di bahagian Timur yang menggunakan sistem telekomunikasi yang paling moden pada era tersebut (Amarjit Kaur, 1985).

Pada tahun 1902, Jabatan Pos dan Jabatan Telegraf di Negeri-Negeri Selat telah digabungkan menjadi satu jabatan oleh pentadbiran British untuk menyelaraskan sistem perhubungan dan komunikasi di Negeri-Negeri Selat. Dengan adanya pentadbiran yang sistematik, sistem komunikasi di Negeri-Negeri Selat telah mula berkembang dengan pesat dengan penambahan talian dan perluasan jaringan telefon dan telegraf di seluruh NegeriNegeri Selat dan Tanah Melayu (Koh, Zubaidah \& Azlizan, 2020). Pada awal abad ke-20 juga teknologi wireless juga diperkenalkan di Singapura dan Pulau Pinang bagi meningkatkan lagi perkhidmatan telegraf supaya mesej disampaikan dengan lebih mudah (Colonial Office: CO275/94, 1915). Pentadbiran British telah mengambil langkah untuk memperluaskan jaringan komunikasi dari Negeri-Negeri Selat ke Negeri-Negeri Melayu yang lain. Hal ini secara tidak langsung telah memantapkan lagi sistem komunikasi di Negeri-Negeri Selat. Selain itu, perkembangan ekonomi juga mendorong kepada perkembangan sistem komunikasi. Usahausaha yang dilakukan oleh British dalam meningkatkan kualiti perkhidmatan telefon dan telegraf telah memberi manfaat kepada pentadbiran dan ekonomi Negeri-Negeri Selat.

\section{KAJIAN LITERATUR}

Sistem perhubungan di Tanah Melayu pada era kolonial British telah banyak dikaji oleh para sarjana. Antara kajian mengenai bidang perhubungan dibahagikan kepada pengangkutan, komunikasi, pos dan telegraf. Penelitian ke atas kajian-kajian sedia ada terhadap sistem komunikasi mendapati bahawa belum ada kajian secara mendalam tentang telefon dan telegraf di Negeri-Negeri Selat dari tahun 1900 hingga sebelum era Perang Dunia Kedua. Perbincangan mengenai bidang perhubungan pada era kolonial lebih banyak menekankan perkembangan sistem pengangkutan di Tanah Melayu oleh pentadbiran British. Amarjit Kaur (1985) telah membuat kajian ke atas perkembangan pengangkutan dan komunikasi di Tanah Melayu pada tahun 1870 hingga 1957. Kajiannya membincangkan perkembangan sistem pengangkutan dengan pembinaan jalan raya dan landasan kereta api di Tanah Melayu sejak 1900-an disebabkan pengeluaran getah dan bijih timah yang mendapat permintaan tinggi di pasaran dunia pada ketika itu. Kajian Amarjit Kaur juga menyatakan bahawa sistem komunikasi turut mengalami perubahan di bawah pemerintahan British. Perubahan ini dilakukan oleh British sejak tahun 1870-an akibat perkembangan aktiviti perlombongan. Walau bagaimanapun, kajian beliau lebih tertumpu kepada perkembangan sistem pengangkutan dan komunikasi di Perak, Selangor, Negeri Sembilan, Pahang, Kedah dan Kelantan berbanding dengan Negeri-Negeri Selat.

Perkembangan sistem komunikasi juga dikaji oleh Azharudin Mohamed Dali (2001) yang memfokuskan kepada sejarah telekomunikasi di Selangor pada tahun 1874 hingga 1896. Kajian ini menyatakan bahawa perkembangan telekomunikasi di Britain banyak mempengaruhi sistem telekomunikasi di tanah jajahannya seperti Tanah Melayu. Kajian Azharudin membincangkan bahawa sistem telekomunikasi berkembang pesat di Selangor 
sekitar tahun 1887 hingga 1891 dan turut diperluaskan ke Negeri-Negeri Melayu yang lain. Penggunaan telefon juga membawa Selangor ke satu zaman yang moden. Sistem telefon dan telegraf telah melicinkan urusan pentadbiran British di Selangor selain dapat berhubung dengan pusat pentadbiran British di Singapura. Namun begitu, telekomunikasi di Selangor masih sukar untuk mengembangkan lagi jaringan telegraf kerana segala tindakan mereka adalah tertakluk kepada kelulusan dari pusat pentadbiran di Singapura.

Selain Amarjit Kaur dan Azharudin, sarjana-sarjana lain juga membuat kajian ke atas sistem perhubungan di Tanah Melayu era kolonial. Namun begitu, kajian mereka hanya tertumpu kepada perkembangan sistem pengangkutan dan tidak membincangkan sistem komunikasi. Antaranya seperti Chai Hon-Chan (1967), Joginder Singh Jessy (1979), Barbara Watson Andaya dan Leonard Y. Andaya (1982) membincangkan perkembangan industri getah dan bijih timah di Tanah Melayu yang telah membawa kepada kemajuan sistem pengangkutan di Tanah Melayu. Jalan raya banyak dibina untuk kegunaan pengangkutan getah dan landasan kereta api dibina untuk penghantaran bijih timah dari kawasan perlombongan ke kota pelabuhan. Sarjana-sarjana ini lebih memberi fokus dalam membincangkan perkembangan sistem perhubungan dari aspek pengangkutan tetapi tidak membincangkan sistem telekomunikasi dan perkhidmatan pos yang turut disediakan oleh British di negeri-negeri pantai barat Tanah Melayu.

Bagi meneliti bidang kajian ini, penyelidik juga membuat rujukan terhadap kajian sarjana dalam bidang berkaitan komunikasi bagi meneliti kepentingan sistem komunikasi kepada British dan juga masyarakat kini. Antaranya Muhammad Aslah Akmal Azmi dan Mohd. Samsudin (2018) yang membincangkan British telah menggunakan propaganda sebagai medium komunikasi utama dalam mendapatkan sokongan masyarakat tempatan Tanah Melayu dan menanam sikap anti Turki dan Jerman dalam kalangan mereka semasa Perang Dunia Pertama. Hal ini juga membuktikan bahawa sistem komunikasi efektif amat diperlukan oleh pentadbiran British untuk penyebaran maklumat di Tanah Melayu semasa era kolonial. Selain itu, bidang komunikasi juga terus berkembang selepas kemerdekaan Tanah Melayu pada tahun 1957 dan menjadi elemen penting dalam pembangunan masyarakat sehingga ke hari ini. Sebagai contoh, akhbar turut memainkan peranan sebagai medium komunikasi dalam penyampaian informasi tentang dasar kerajaan kepada masyarakat selepas Pilihanraya Umum 1969 (Azlizan \& Norlilawati, 2020). Komunikasi berkesan amat penting terutamanya di Malaysia yang terdiri daripada komuniti berbilang kaum dalam mengelakkan berlakunya penyebaran khabar angin yang negatif (Al-Amril \& Shahizan, 2018). Malah, komunikasi telah menjadi salah satu bidang pendidikan yang diperkenalkan di institusi pengajian tinggi di seluruh Malaysia sejak tahun 1970-an (Syed, 2019).

\section{METODOLOGI KAJIAN}

Metodologi yang digunakan dalam menjalankan kajian ini ialah kaedah kualitatif. Penelitian adalah berdasarkan kepada metodologi sejarah dengan menjadikan bahan primer sebagai sumber analisis utama. Bagi menjalankan penyelidikan ini, penyelidik telah melakukan kajian kepustakaan untuk memperoleh bahan rujukan. Penyelidik mendapatkan bahan primer dari Arkib Negara Malaysia dan sumber sekunder dari perpustakaan. Antara sumber primer yang dirujuk adalah seperti fail dan dokumen era kolonial British di Negeri-Negeri Selat berkaitan dengan perkhidmatan telefon dan telegraf. Fail CO 273 Colonial Office: Straits Settlements Original Correspondence dan CO 275 Colonial Office: Straits Settlements Sessional Papers telah dirujuk untuk mendapatkan minit mesyuarat, surat-menyurat, laporan pegawai British, kertas 
kerja serta dokumen-dokumen lain yang mencatat maklumat berkaitan sistem komunikasi di Tanah Melayu terutamanya Negeri-Negeri Selat dari tahun 1902 hingga 1938.

Sumber sekunder juga dirujuk sebagai maklumat tambahan kepada beberapa fakta yang dibincangkan dan juga berkaitan dengan topik penyelidikan selain menjadi pengenalan kepada perkembangan perkhidmatan telefon dan telegraf di Negeri-Negeri Selat. Sumber sekunder yang dirujuk adalah seperti buku dan artikel yang merupakan kajian-kajian lepas dalam bidang perhubungan dan komunikasi. Kedua-dua sumber ini telah dirujuk dan dianalisis untuk melengkapkan penyelidikan ini. Namun, sumber primer iaitu rekod-rekod British diberi keutamaan bagi memastikan hasil penyelidikan lebih berkualiti dan lebih sahih serta berpandukan kepada kaedah penyelidikan sejarah.

\section{HASIL KAJIAN DAN PERBINCANGAN}

Sistem komunikasi mula berkembang sejak campur tangan pentadbiran British di NegeriNegeri Selat. Sebelum tahun 1902, Bahagian Telegraf adalah terletak di bawah pentadbiran Jabatan Kerja Awam Negeri-Negeri Selat. Bahagian ini hanya berfokus kepada penyediaan talian telefon dan telegraf di Negeri-Negeri Selat. Pentadbiran kolonial mendapati bahawa talian telegraf juga dipasang serentak dengan pejabat pos dan sesetengah pejabat pos juga dijadikan sebagai stesen pertukaran bagi talian telefon. Sehubungan itu, kolonial British mengambil keputusan untuk menggabungkan Jabatan Pos dan Bahagian Telegraf sebagai satu jabatan bagi menguruskan semua perkhidmatan yang berkaitan. Pada tahun 1902, Bahagian Telegraf telah berpindah dan menjadi sebahagian daripada Jabatan Pos dan Telegraf sepenuhnya (Colonial Office: CO275/64, 1902). Sejak itu, British telah banyak membuat pembaharuan dalam sistem telekomunikasi mulai tahun 1902 dengan menambah talian-talian telefon dan telegraf di seluruh Negeri-Negeri Selat. Jaringan turut diperluaskan ke NegeriNegeri Melayu yang lain bagi memudahkan urusan pentadbiran British. Pada masa yang sama, teknologi baharu iaitu teknologi wireless juga diperkenalkan oleh pentadbiran British di Negeri-Negeri Selat. Perkembangan sistem komunikasi ini juga turut menyumbang kepada para penduduk tempatan.

\section{Kemudahan Sistem Telegraf}

Telegraf mula terletak di bawah Jabatan Pos dan Telegraf pada tahun 1902 selepas penstrukturan organisasi Jabatan Pos (Colonial Office: CO275/66, 1903). Sejak itu, pelbagai pembaharuan telah dilakukan oleh kolonial British terhadap sistem telegraf di Negeri-Negeri Selat untuk membekalkan perkhidmatan komunikasi dan perhubungan yang lebih efisien kepada penduduk Negeri-Negeri Selat. Antara tahun 1902 hingga tahun 1919, tumpuan utama British adalah pada perkembangan jaringan talian telegraf dalam Negeri-Negeri Selat dan hubungan dengan beberapa buah negeri di sekitarnya. Pada tahun 1903, talian telegraf hanya terdapat di Pulau Pinang dan Melaka. Kolonial British mempunyai 12 batu talian bawah laut dan 83 batu talian darat di Pulau Pinang dan Province Wellesley. Terdapat empat buah pejabat telegraf di Pulau Pinang dan empat buah pejabat telegraf di Province Wellesley. Di Melaka pula, British hanya memiliki 39 batu talian darat dengan sebuah pejabat telegraf sahaja (Colonial Office: CO275/68, 1905). Jaringan yang terhad menyebabkan telegram tidak dapat dihantar ke semua kawasan dalam Negeri-Negeri Selat. Hal ini telah menyebabkan pentadbiran kolonial telah membuat perancangan untuk memperluaskan jaringan talian telegraf ke negeri-negeri lain terutamanya menghubungkan ketiga-tiga Negeri-Negeri Selat. 
Dalam usaha meningkatkan perkhidmatan telegraf, kolonial British telah memasangkan talian telegraf dari Pulau Pinang ke Kuala Lumpur sepanjang landasan kereta api pada tahun 1904. Talian baharu ini mula diguna pakai pada bulan Oktober. Hasil pemasangan talian baharu ini, penghantaran telegram antara Pulau Pinang dan Selangor menjadi lebih mudah dan mempercepatkan urusan pentadbiran kolonial (Colonial Office: CO275/70, 1905). Pada tahun 1906 pula, pentadbiran British telah memulakan kerja-kerja pemasangan talian baharu untuk menghubungkan talian telegraf dari Pulau Pinang ke Singapura (Colonial Office: CO275/74, 1907). Singapura dan Pulau Pinang sebagai pusat bandar yang menjadi tumpuan pembangunan oleh pentadbiran kolonial British amat memerlukan sistem perhubungan yang efektif bagi memastikan mesej dan maklumat penting dapat dihantar dengan cepat. Oleh itu, langkah ini adalah bagi memudahkan proses penghantaran maklumat dari utara ke selatan dan lebih menjimatkan masa dan tenaga.

Pada tahun 1908, talian yang menghubungkan Singapura dan Pulau Pinang telah siap dipasang dan bersedia untuk digunakan oleh pentadbiran dan masyarakat umum. Pada masa yang sama, satu talian telegraf tambahan dari Kuala Lumpur ke Singapura juga dipasang bagi membolehkan mesej dapat dihantar sekiranya talian utama berlaku kerosakan atau mempunyai masalah. Jumlah kepanjangan talian telegraf yang dimiliki kolonial British adalah sepanjang 243 batu di darat dan 29 batu bawah laut (Colonial Office: CO275/79, 1910). Dengan adanya rangkaian telegraf yang lengkap ini, urusan pentadbiran menjadi lebih lancar. Walaupun jarak antara Pulau Pinang dan Singapura agak jauh, tetapi mesej penting dapat dihantar dengan segera melalui talian telegraf baharu. Selain itu, perkhidmatan telegraf juga dibuka untuk penggunaan awam. Hal ini kerana selain penyambungan Pulau Pinang dan Singapura, kolonial British juga turut memasangkan talian telegraf antara Pulau Pinang dan Bangkok. Oleh itu, penduduk di Bangkok juga dapat menghantar telegram kepada penduduk di Negeri-Negeri Selat. Pendapatan hasil perkhidmatan telegraf meningkat pada tahun 1909 iaitu daripada $\$ 20,428.75$ kepada $\$ 25,200.13$ menunjukkan bahawa perkhidmatan telegraf yang semakin meluas mendapat sambutan dalam kalangan pegawai pentadbiran dan penduduk tempatan (Colonial Office: CO275/81, 1910).

Mulai tahun 1911, British telah memperluaskan rangkaian telegraf ke negeri-negeri Melayu yang lain. Antara yang diberikan tumpuan ialah negeri Johor. Negeri Johor merupakan bandar yang terdekat dengan kota pelabuhan penting iaitu Singapura juga memerlukan sistem telegraf bagi memudahkan komunikasi. Pedagang bukan sahaja menjalankan aktiviti perdagangan di Singapura tetapi juga akan ke Johor Bahru. Oleh itu, talian baharu untuk seksyen Singapura-Johor juga dipasang dan mula digunakan pada tahun 1912 (Colonial Office: CO275/87, 1912). Pada tahun 1916, talian telegraf baharu juga dipasang dari Pulau Pinang ke Johor. Pada tahun yang sama juga, terdapat cadangan baharu yang diluluskan iaitu pemasangan talian telegraf Melaka-Muar-Batu Pahat. Hal ini kerana Muar, Batu Pahat dan Johor Bahru juga merupakan bandar utama yang menjadi tumpuan pentadbiran British. Selain itu, kedudukan Johor yang terletak di antara Melaka dan Singapura, menjadikannya strategik dan amat diperlukan untuk mempunyai sistem perhubungan yang terkini untuk penghantaran maklumat.

Bagi meningkatkan kualiti perkhidmatan telegraf, sistem telegraf juga dipasang di pejabat pos dan sub-pejabat pos. Sebagai permulaan, sistem telegraf telah dipasang di Pejabat Pos Alor Gajah pada 3 April 1916 (Colonial Office: CO275/98, 1918). Hal ini adalah untuk memudahkan urusan penduduk tempatan dan juga pegawai-pegawai British. Sebelum itu, sistem telegraf hanya terdapat di Pejabat Telegraf yang khas untuk penghantaran telegram 
sahaja. Dengan pemasangan sistem telegraf di Pejabat Pos, ia menjadi satu langkah yang baik untuk memudahkan para pengguna. Pengguna boleh menyelesaikan pelbagai urusan di satu tempat yang sama iaitu kiriman surat, kiriman wang pos dan juga kiriman telegram. Bagi para pegawai juga dapat menjimatkan masa dalam menjalankan tugas. Langkah ini seterusnya diperluaskan lagi ke sub-pejabat pos dalam Negeri-Negeri Selat untuk membolehkan perkhidmatan telegraf dinikmati oleh penduduk di seluruh koloni British (Colonial Office: CO275/105, 1923). Dari tahun 1916 hingga tahun 1922, sebanyak tujuh pejabat pos dan subpejabat pos telah dipasang sistem telegraf untuk kegunaan awam.

\begin{tabular}{cccc} 
Jadual 1: Pemasangan Sistem Telegraf di Pejabat Pos dan Sub-Pejabat Pos Negeri-Negeri Selat \\
\hline Tahun & Melaka & Pulau Pinang & Singapura \\
\hline 1916 & Pejabat Pos Alor Gajah & & \\
1919 & & $\begin{array}{c}\text { Pejabat Pos Pulau } \\
\text { Pinang }\end{array}$ \\
1921 & Sub-Pejabat Pos & & Sub-Pejabat Pos Sepoy \\
& Durian Tunggal & & Lines \\
& Sub-Pejabat Pos & & \\
& Asahan & & \\
& Sub-Pejabat Pos & Sub-Pejabat Pos Pitt \\
& Merlimau & Street & \\
\hline
\end{tabular}

Sumber: CO275 Laporan Tahunan Negeri-Negeri Selat Tahun 1916 hingga 1922

Dengan kemajuan teknologi yang ada pada ketika itu, pentadbiran kolonial British juga memperuntukkan dana untuk pemasangan peralatan berkelajuan tinggi (high speed instruments) bagi sistem telegraf pada tahun 1918. Peralatan ini dipasang antara Singapura dan Pulau Pinang untuk menyediakan perkhidmatan penghantaran yang lebih laju dan stabil. Teknologi baharu dibawa masuk oleh Consulting Engineers dari England untuk dipasang pada talian telegraf di Negeri-Negeri Selat. Selain itu, pentadbiran British juga memasangkan talian baharu iaitu six cored double armoured cable yang lebih berkualiti dan lebih daya ketahanan. Talian logam juga dipasang untuk menghubungkan telegraf antara Pulau Pinang dan Melaka seperti Butterworth dan Penaga, Butterworth dan Bukit Mertajam, Butterworth dan Simpang Ampat, Simpang Ampat dan Bukit Mertajam, serta Butterworth dan Simpang Ampat. Pemasangan talian baharu mendapat maklum balas yang memberangsangkan daripada para pengguna di kawasan yang terlibat. Hal ini kerana gangguan dan kerosakan telah dikurangkan dan para pengguna amat berpuas hati dengan perkhidmatan telegraf yang disediakan (Colonial Office: CO275/100, 1920). Usaha naik taraf ini diteruskan pada tahun 1919 dengan pengenalan teknologi baharu iaitu quadruplex yang membolehkan dua mesej dari dua arah dihantar secara serentak. Teknologi baharu ini dipasang antara Singapura dan Pulau Pinang. Beberapa ujian telah dilakukan untuk memastikan teknologi baharu ini dapat digunakan dengan baik. Hasilnya membuktikan quadruplex berfungsi dengan baik iaitu dua mesej dari dua arah dapat dihantar secara serentak pada masa yang sama. Hal ini telah menjimatkan masa dan mesej dapat dihantar dengan lebih cepat. Teknologi ini telah bersedia untuk dibuka kepada pengguna awam (Colonial Office: CO275/101, 1921).

Mulai tahun 1920-an, lebih banyak kerja naik taraf dilakukan ke atas sistem telegraf di Negeri-Negeri Selat. Kegunaan telegraf juga semakin meluas antara Negeri-Negeri Selat dan Negeri-Negeri Melayu yang lain. British telah memperluaskan pemerintahannya ke seluruh 
Tanah Melayu. Oleh itu, adalah perlu untuk mempunyai sistem telegraf yang lebih sempurna untuk memastikan maklumat dapat dihantar melalui sistem telegraf. Talian-talian lama telah ditukar dengan talian baharu yang mampu menghantar mesej yang banyak berbanding talian pada awal tahun 1900-an. Talian-talian dipasang sepanjang landasan kereta api di Tanah Melayu yang telah menghubungkan beberapa negeri dari utara ke selatan. Talian terus (direct telegraph lines) juga dipasang dari Melaka ke Singapura dan tidak perlu melalui stesen pertukaran. Ini telah memudahkan lagi urusan penghantaran telegram di antara NegeriNegeri Selat (Colonial Office: CO275/107, 1924). Pada tahun 1924 pula, kesemua sub-pejabat pos di Melaka telah disambungkan talian telegraf dan dikawal oleh Pejabat Pos Utama Melaka yang merupakan pusat pengawalan telegraf di Melaka (Colonial Office: CO275/112, 1926). Penghantaran telegram dalam Melaka sudah tidak menjadi masalah kerana semua talian telah bergabung dan terletak di bawah kawalan pusat.

Sejak tahun 1920, tumpuan utama kolonial British ialah penambahan talian dan penggantian talian lama di seluruh Negeri-Negeri Selat. Selain itu, Pejabat Telegraf juga ditambah di Negeri-Negeri Selat untuk menampung penggunaan sistem telegraf yang semakin meningkat. Contohnya Pejabat Telegraf yang dibuka di Runnymede Hotel, Pulau Pinang pada 22 Oktober 1928 dan Sub-Pejabat Newton, Singapura pada 5 November 1928 (Colonial Office: CO275/121, 1929). Pada tahun 1930, Teleprinter diperkenalkan bagi menghantar dan menerima telegram yang ditaip melalui talian dan boleh menggantikan mesej morse (Colonial Office: CO275/136, 1936). Pada era ini, typewriter telah diperkenalkan dan dibawa masuk untuk diguna pakai dalam sistem telegraf di Negeri-Negeri Selat. Creed Typewriter Perforator telah dipasang di Singapura dan Pulau Pinang untuk menguruskan telegram pada tempoh yang sibuk (Colonial Office: CO275/126, 1932). Di sini dapat dilihat bahawa sistem telegram mendapat sambutan dalam kalangan penduduk tempatan dan pegawai British. Bagi menyelesaikan jumlah telegram yang diterima dan dihantar setiap hari, teknologi baharu dibawa masuk bagi memudahkan urusan penghantaran telegraf. Pada tahun 1932, satu lagi pembaharuan yang diperkenalkan oleh Jabatan Pos dan Telegraf iaitu pengenalan sistem penghantaran telegram melalui talian telefon di 34 buah pejabat pos kecil. Hal ini juga turut mengurangkan kos melatih staf baharu kerana staf yang sedia ada telahpun mempunyai kemahiran mengendalikan operasi morse (Colonial Office: CO275/131, 1933). Pada masa yang sama, para pengguna boleh menghantar telegram di pejabat pos yang terdekat.

Sistem telegraf merupakan satu sistem yang banyak digunakan oleh pentadbiran kolonial dalam penghantaran mesej telegram. Pelbagai usaha telah dilakukan oleh pihak kolonial British melalui Jabatan Pos dan Telegraf. Antaranya termasuklah pemasangan talian telegraf untuk menghubungkan seluruh kawasan Negeri-Negeri Selat dan seterusnya meluaskan rangkaian ke Negeri-Negeri Melayu yang lain di Tanah Melayu terutamanya negeri pantai barat yang menjadi penghubungan kepada Pulau Pinang, Melaka dan Singapura. Seterusnya, pelbagai teknologi baharu dibawa masuk dari England untuk dipasang dan digunakan di Neger-Negeri Selat bagi meningkatkan kualiti perkhidmatan yang sedia ada. Talian-talian lama juga ditukar kepada talian baharu yang membolehkan lebih banyak mesej dihantar dalam masa yang sama tanpa mengganggu penghantaran mesej yang lain. Kesemua usaha ini telah memberi kesan positif kepada sistem pentadbiran dan penduduk tempatan. Penyampaian mesej pentadbiran British melalui telegram dapat dihantar dengan segera dan pada masa yang sama, orang awam juga dapat menikmati kemudahan yang disediakan oleh Jabatan Pos dan Telegraf ini (Colonial Office: CO275/126, 1932). Sebagai contoh, pada tahun 1920-an, statistik penggunaan sistem telegraf telah menunjukkan peningkatan seperti berikut: 
Jadual 2: Statistik Penggunaan Sistem Telegraf di Negeri-Negeri Selat 1920-1929

\begin{tabular}{cccc}
\hline Tahun & $\begin{array}{c}\text { Jumlah Telegraf } \\
\text { Diterima }\end{array}$ & $\begin{array}{c}\text { Jumlah Telegraf } \\
\text { Dihantar }\end{array}$ & $\begin{array}{c}\text { Pendapatan } \\
\mathbf{( \$ )}\end{array}$ \\
\hline 1920 & 491,003 & 581,310 & 138,598 \\
1921 & 370,236 & 497,077 & 144,282 \\
1922 & 318,053 & 467,421 & 170,040 \\
1923 & 336,778 & 453,859 & 161,866 \\
1924 & 356,415 & 451,360 & 158,008 \\
1925 & 438,143 & 570,740 & 192,448 \\
1926 & 486,005 & 626,161 & 237,006 \\
1927 & 496,127 & 593,703 & 245,236 \\
1928 & 486,365 & 565,150 & 232,849 \\
1929 & 498,518 & 592,269 & 231,055 \\
\hline
\end{tabular}

Sumber: CO275 Laporan Tahunan Jabatan Pos dan Telegraf 1920 - 1929

Peningkatan statistik penggunaan menunjukkan sistem telegraf antara perkhidmatan yang mendapat sambutan dalam kalangan pegawai-pegawai pentadbiran dan juga penduduk awam. Penambahan dan naik taraf talian telegraf turut menyediakan perkhidmatan yang lebih efektif serta memberi manfaat kepada para pengguna dalam proses penghantaran mesejmesej.

\section{Kemudahan Sistem Telefon}

Kemudahan sistem telefon juga antara teknologi komunikasi moden yang diperkenalkan di Negeri-Negeri Selat. Sistem telefon diambil alih oleh Jabatan Pos dan Telegraf pada tahun 1902. Sejak itu, Jabatan Pos dan Telegraf bawah pemerintahan kolonial British juga memberi tumpuan dalam membawa masuk teknologi baharu dari segi peralatan dan talian telefon. Perkhidmatan telefon telah diperluaskan di seluruh Negeri-Negeri Selat seterusnya penambahan talian untuk berhubung dengan Negeri-Negeri Melayu yang lain. Tujuan utamanya adalah untuk menyediakan sistem komunikasi yang lebih sempurna bagi memudahkan perhubungan antara pegawai koloni dan melicinkan pentadbiran British. Hal ini dapat dilihat apabila perkhidmatan telefon diambil alih oleh Jabatan Pos dan Telegraf pada tahun 1902, panjang talian telefon di Singapura hanya 78 batu sahaja dan semuanya digunakan oleh polis dan jabatan-jabatan pentadbiran British di Singapura. Hasil usaha pentadbiran British, talian telefon juga mula terbuka kepada penggunaan oleh masyarakat awam dengan mewujudkan telefon awam.

Pada peringkat awal, pentadbiran kolonial British memberi fokus dalam pemasangan talian telefon dan juga ibu sawat. Hal ini kerana pada awal pentadbiran Jabatan Pos dan Telegraf, talian telefon di Negeri-Negeri Selat amat terhad iaitu 78 batu di Singapura, 165 batu di Pulau Pinang dan Province Wellesley, serta 147 batu di Melaka. Tidak semua tempat dihubungkan dengan talian telefon (Colonial Office: CO275/68, 1905). Hal ini amat menyukarkan pihak pentadbiran untuk menyampaikan maklumat penting dengan kadar segera. Telefon merupakan alat perhubungan dan komunikasi yang boleh menyampaikan sesuatu mesej dengan kadar yang segera berbanding dengan surat-menyurat dan telegram. Sehubungan itu, pada tahun 1904, banyak talian telefon baharu telah dipasang di Singapura yang menghubungkan balai polis antara Gaylang dan Changi, Thomson Road dan Chan Chu Kang. Di Pulau Pinang juga, 37 talian baharu telah ditambah pada ibu sawat utama Pulau Pinang (Colonial Office: CO275/70, 1905). Talian telefon di Pulau Pinang banyak ditambah tahun demi tahun. Pada tahun 1907, 43 lagi talian baharu telah dipasang termasuk 
pemasangan talian telefon yang menghubungkan ibu sawat dengan Leper Hospital, Pulau Jerejak dan Stesen Kuarantin. 27 talian polis juga disambungkan ke ibu sawat (Colonial Office: CO275/77, 1908). Talian baharu yang dipasang di Pulau Pinang pada tahun 1908 membolehkan polis dapat menghubungi polis di balai polis yang lain pada bila-bila masa tidak kira waktu siang atau waktu malam.

Pada tahun 1908, sebanyak 80 talian telefon baharu dipasang di Pulau Pinang dan mempunyai 371 pelanggan. 31 talian telefon baharu merupakan talian untuk polis (Colonial Office: CO275/79, 1910). Pada era ini, tumpuan pemasangan talian telefon diberi keutamaan dalam keselamatan awam iaitu polis dan hospital. Penyambungan talian telefon ke balai polis membolehkan sebarang aduan dan laporan diterima oleh polis untuk tindakan segera.

A complete and up-to-date system for interconnecting all the police stations would undoubtedly be of immense service in keeping down crime and in catching the criminals. (Colonial Office: CO273/394/28355, 1912).

Hal ini turut menjamin keselamatan para penduduk di Negeri-Negeri Selat. Selain itu, talian telefon di balai polis juga penting untuk kolonial British mengawal penduduk tempatan bagi mengelakkan berlaku sebarang pemberontakan di kawasan penjagaan mereka. Pemasangan talian telefon ke hospital juga dilihat sebagai satu langkah untuk menjaga kebajikan penduduk dari segi kesihatan. la telah memudahkan urusan perhubungan di hospital kerana dapat menyediakan perkhidmatan bantuan rawatan yang lebih cepat setelah menerima laporan oleh pihak hospital.

Antara tahun 1910 hingga 1920, Jabatan Pos dan Telegraf memberi tumpuan dalam menukar papan suis, penambahan talian dan pemasangan ibu sawat telefon. Pada tahun 1911, ibu sawat baharu di Melaka telah dipasang dan mula digunakan sebagai pusat transmisi telefon (Colonial Office: CO275/87, 1912). Pada tahun yang sama, satu cadangan telah diluluskan untuk pemasangan talian telefon bagi menghubungkan Pulau Pinang dengan Singapura. Talian tersebut telah melalui beberapa negeri Melayu dari utara ke selatan. Talian telefon ini diperlukan untuk menghubungkan talian telefon di kedua-dua buah negeri koloni tersebut (Colonial Office: CO273/375/41617, 1911). Ibu sawat di Simpang Ampat juga menukar papan suis yang sama. Papan suis yang baharu dapat menampung penggunaan talian telefon yang lebih banyak memandangkan jumlah pelanggan telefon semakin meningkat (Colonial Office: CO275/94, 1915). Pada tahun 1916, sistem telefon di Melaka telah menunjukkan perkembangan yang amat memberangsangkan. Pengguna yang mendaftar talian telefon untuk kegunaan peribadi telah menunjukkan peningkatan dari 87 pelanggan pada tahun 1915 kepada 117 pelanggan pada tahun 1916. Hal ini menyebabkan lebih banyak talian telefon telah dipasang di Melaka bagi menampung keperluan masyarakat terhadap talian telefon (Colonial Office: CO275/98, 1918). Pada tahun 1918, papan suis yang baharu telah dipasang di Melaka dan menggantikan semua litaran tanah dengan litaran logam supaya lebih tahan dan tidak mudah rosak (Colonial Office: CO275/100, 1920).

Di Pulau Pinang pula, pada tahun 1914, papan suis di Province Wellesley telah ditukarkan dengan papan suis yang baharu dan moden bagi memastikan talian telefon tidak mengalami gangguan kerosakan yang kerap. Seterusnya, pada tahun 1905, satu lagi ibu sawat telah dipasang di Caledonia, Province Wellesley, yang telah menghubungkan semua estet getah di Caledonia. Pemasangan ibu sawat ini telah menunjukkan bahawa jaringan dan rangkaian talian telefon telah semakin meluas. Estet-estet getah juga dapat berhubung 
sesama mereka dengan lebih mudah. Hal ini turut menunjukkan bahawa pembangunan bukan sahaja tertumpu kepada kawasan bandar utama sahaja tetapi termasuklah kawasan estet. Kawasan estet merupakan tumpuan penempatan imigran India. Pembaharuan ini turut menyediakan kemudahan telekomunikasi kepada masyarakat India yang menetap di kawasan estet. Selain itu, para pelabur dan syarikat getah juga menggunakan kemudahan ini untuk berhubung dengan kota-kota pelabuhan bagi tujuan jualan dan eksport getah. Pada tahun yang sama juga, satu papan suis telah dipasang di Pejabat Pos Government Hill, Pulau Pinang bagi menyediakan perkhidmatan talian telefon kepada perumahan banglo di kawasan tersebut untuk penduduk di kawasan itu bagi memudahkan proses perhubungan. Kebanyakan penduduk di sana juga merupakan pegawai British dan para pedagang yang amat memerlukan kemudahan ini untuk urusan pentadbiran dan ekonomi (Colonial Office: CO275/96, 1916). Seterusnya pada tahun 1918, ringing transformer telah dipasangkan di Pusat Pertukaran Talian Pulau Pinang untuk menjana ringing pada waktu siang bagi meringankan beban dan tugas staf-staf yang bertugas di ibu sawat. Sebelum pengenalan ringing transformer di NegeriNegeri Selat, operator yang bertugas perlu membuat pertukaran panggilan secara manual. Pengenalan ringing transformer dapat membantu membuat deringan telefon tanpa memerlukan tenaga manusia (Colonial Office: CO275/100, 1920). Pada tahun 1920 pula, British telah menukar talian telefon polis yang baharu di Province Wellesley dan pemasangan peralatan baharu di semua balai polis dan papan suis di Penaga, Sungei Bakap dan Nibong Tebal. Talian polis juga disambungkan ke ibu sawat di Butterworth, Bukit Mertajam dan Simpang Ampat (Colonial Office: CO275/103, 1922). Di Pulau Pinang juga talian polis amat diberi penekanan dalam pembaharuan dan pemasangan peralatan baharu. Hal ini kerana talian polis penting untuk penyampaian maklumat sekiranya berlaku apa-apa kes jenayah di Pulau Pinang. Sebagai contoh, pergaduhan telah berlaku antara penduduk Cina di Prangin Road, Pulau Pinang pada Jun 1919. Laporan polis telah dibuat melalui telefon dan pergaduhan itu berjaya diselesaikan dengan cepat selepas kehadiran polis.

A telephone cable at Prangin Road, Penang, gave trouble in June but successfully repaired. In this month there was also serious rioting amongst the Chinese. The Telephone staff were thanked by the Police and Military for the attention given. (Colonial Office: CO275/101, 1921).

Di Singapura, talian telefon pentadbiran British kebanyakannya terhad kepada pejabatpejabat pentadbiran sahaja berbanding dengan talian di Pulau Pinang dan Melaka. Talian telefon di Singapura pada ketika itu masih dikendalikan oleh Oriental Telephone Company sebagai syarikat swasta yang mula menguasai industri telefon di Singapura sejak tahun 1882 (Turnbull, 2009). Oleh itu, pentadbiran British di Singapura hanya menumpukan pembangunan talian telefon untuk jabatan-jabatan pentadbiran sahaja. Hal ini juga memudahkan pegawai-pegawai British di negeri-negeri Melayu yang lain untuk menyampaikan maklumat kepada Gabenor di Singapura. Sepanjang tahun 1910 hingga 1920, tumpuan pembangunan sistem telefon oleh British hanya pada penyambungan talian telefon di stesen pertukaran talian telefon polis seluruh Singapura ke satu pusat pertukaran bagi memudahkan lagi sistem perhubungan antara balai polis di seluruh Singapura. Penyambungan talian ini telah dilakukan pada tahun 1916 (Colonial Office: CO275/98, 1918). 
Antara tahun 1921 hingga 1930 pula, pentadbiran British juga sentiasa berusaha untuk pemasangan talian dan papan suis yang baharu. Selain itu, talian disambungkan dengan Negeri-Negeri Melayu yang lain serta menyediakan talian telefon awam untuk digunakan masyarakat setempat. Pada tahun 1921, telefon awam telah dipasang di sub-pejabat pos di Pulau Pinang dan Melaka. Di Singapura pula, telefon awam dipasang di sub-pejabat pos dan disambungkan ke ibu sawat Oriental Telephone \& Electric Co. (Colonial Office: CO275/105, 1923). Pengenalan telefon awam ini merupakan satu pembaharuan yang mendatangkan manfaat kepada masyarakat umum kerana semua penduduk dapat menikmati perkhidmatan ini dan mereka juga tidak perlu mendaftar talian telefon di rumah. Kemudahan ini juga semakin bertambah pada setiap tahun di Negeri-Negeri Selat. Contohnya pada tahun 1922, telefon awam telah dipasang di sub-pejabat pos Merlimau, Asahan dan Durian Tunggal, Melaka (Colonial Office: CO275/107, 1924). Pada tahun 1924 pula, talian telefon yang lama juga digantikan dengan talian baharu serta menukarkan papan suis yang baharu. Bagi mengelakkan talian telefon menghadapi gangguan, pokok-pokok juga ditebang untuk memberi laluan kepada pemasangan talian telefon baharu (Colonial Office: CO275/112, 1926). Pada tahun 1925 dan 1926, stesen pertukaran talian telefon juga dipasang. Talian-talian bawah tanah juga ditambah dan mula digunakan oleh masyarakat awam. Bagi menampung penggunaan telefon yang semakin meningkat, banyak stesen pertukaran dan ibu sawat telah dipasang bagi menghubungkan semua talian telefon (Colonial Office: CO275/124, 1930).

Antara tahun 1930-an, banyak stesen pertukaran dan ibu sawat baharu telah dipasang. Banyak peralatan baharu juga dibawa masuk dari England untuk menggantikan peralatan lama yang sudah mempunyai masalah. Peralatan baharu juga lebih stabil dan dapat mengelakkan gangguan talian telefon. Selain itu, kapasiti papan suis baharu juga lebih besar dan boleh menampung penyambungan talian telefon yang lebih banyak. Sebagai contoh, papan suis di Penang Hill telah ditukar dan ditambah dengan papan suis yang berkapasiti besar dengan memasang bateri tambahan untuk memastikan ia dapat menampung semua talian yang disambung ke ibu sawat ini. Pada tahun yang sama, pentadbiran kolonial juga memperluaskan pemasangan talian dan peralatan baharu di kawasan luar bandar untuk menyediakan perkhidmatan telefon di kawasan luar bandar (Colonial Office: CO275/129, 1933). Telefon awam juga disediakan pada era ini untuk digunakan oleh golongan masyarakat berpendapatan rendah. Telefon bukan sahaja terhad kepada jabatan-jabatan pentadbiran kolonial dan kediaman-kediaman pegawai sahaja tetapi juga boleh digunakan oleh masyarakat awam (Colonial Office: CO275/124, 1930).

Telefon merupakan alat komunikasi moden pada zaman kolonial dalam penyampaian maklumat. Usaha pentadbiran British adalah untuk menyediakan perkhidmatan yang lebih baik dan stabil kepada penduduk Negeri-Negeri Selat. Selain itu, talian telefon penting dalam menyambungkan jabatan-jabatan pentadbiran British. Antara agensi yang diberi keutamaan ialah balai polis. Talian polis telah dipasang untuk menghubungkan balai polis di setiap kawasan bagi memastikan segala aduan kes dapat diterima oleh pihak polis dalam masa terdekat untuk mengambil tindakan sewajarnya. Selain itu, pengenalan peralatan baharu di England juga dibawa masuk untuk dipasang di Negeri-Negeri Selat. Peralatan baharu telah diubah suai bagi menampung talian telefon yang banyak memandangkan pelanggan talian telefon di koloni juga semakin meningkat dari tahun ke tahun. 


\section{Kemudahan Teknologi Tanpa Wayar (Wireless)}

Teknologi tanpa wayar merupakan satu teknologi baharu pada zaman kolonial untuk berkomunikasi tanpa talian seperti telefon dan telegraf yang perlu menyambungkan talian dari satu stesen ke satu stesen yang lain. Teknologi tanpa wayar tidak memerlukan talian untuk penghantaran sesuatu mesej. Mesej akan dihantar melalui frekuensi dalam satu lingkungan yang boleh dicapai oleh stesen tanpa wayar. Pada tahun 1914, kerja-kerja pemasangan stesen tanpa wayar di Negeri-Negeri Selat mula dijalankan (Colonial Office: CO273/413/15783, 1914). Terdapat dua kawasan yang dipilih untuk mendirikan stesen wireless iaitu di Penaga, Pulau Pinang dan Paya Lebar, Singapura. Kedua-dua negeri ini dipilih kerana ia merupakan kota pelabuhan utama yang juga menjadi tumpuan pelabuhan di rantau ini. Banyak kapal dagang akan melalui kawasan perairan Selat Melaka dan kapal-kapal telah dilengkapi dengan teknologi tanpa wayar. Stesen tanpa wayar di dua kawasan ini berperanan untuk mengendalikan sistem komunikasi antara kapal dagang dengan kota pelabuhan walaupun kapal dagang masih belum tiba di pelabuhan (Colonial Office: CO273/369/10546, 1911).

Pemasangan stesen tanpa wayar adalah menggunakan peralatan yang terkini yang dibawa masuk dari luar negara. Peralatan yang terpilih merupakan peralatan yang sesuai untuk digunakan di negara yang sentiasa panas seperti di Tanah Melayu. Hal ini bagi memastikan stesen tanpa wayar dapat berfungsi dengan baik walaupun musim di Tanah Melayu adalah panas sepanjang tahun. Selain itu, signal atau isyarat yang disebarkan adalah jelas dan tidak kurang daripada 600 vibrasi per saat supaya dapat didengar dengan jelas tanpa gangguan atmosfera. Stesen yang dibina juga berupaya menghantar gelombang antara 600 hingga 1,800 meter dan mampu transmit mana-mana gelombang antara 600 hingga 2,000 meter. Ini membolehkan penerima mesej terima 30 perkataan pada setiap minit (Colonial Office: CO273/413/15783, 1914). Selain itu, stesen tanpa wayar di Negeri-Negeri Selat telah dibina di tapak yang sesuai untuk membolehkan mesej dihantar dengan baik tanpa gangguan. Berikut merupakan lingkungan komunikasi melalui tanpa wayar:

Jadual 3: Jarak Lingkungan tanpa wayar di Pulau Pinang dan Singapura

\begin{tabular}{lcc}
\hline & $\begin{array}{c}\text { Pulau Pinang } \\
\text { (batu nautika) }\end{array}$ & $\begin{array}{c}\text { Singapura } \\
\text { (batu nautika) }\end{array}$ \\
\hline Air (terbuka) & 350 & 400 \\
Tanah rata & 340 & 300 \\
Tanah tinggi (sehingga 500 kaki) & 280 & 330 \\
Gunung (sehingga 3,000 kaki) & 200 & 250 \\
\hline
\end{tabular}

Sumber: CO273/413/15783, Wireless Telegraph Stations at Singapore and Penang, 29 April 1914

Bagi memastikan stesen tanpa wayar dapat berfungsi dengan baik, langkah berjagajaga telah diambil iaitu menggunakan bahan yang tidak mudah rosak apabila terkena kilat petir. Kuasa akan terputus sekiranya berlaku sebarang kemalangan yang menyebabkan kejutan elektrik. Sejak pembangunan stesen tanpa wayar, tiada laporan kerosakan yang serius dilaporkan. Kerosakan kecil juga dapat diperbaiki dengan kadar segera oleh jurutera terlatih dalam Jabatan Pos dan Telegraf yang bertugas di kedua-dua stesen di Pulau Pinang dan Singapura. Stesen tanpa wayar telah berfungsi dengan baik dan mampu menghantar mesej ke Sarawak (Colonial Office: CO275/100, 1920). Mesej yang diterima dan dihantar juga semakin meningkat. Sebagai contoh, pada tahun 1916, stesen Singapura menerima 502 mesej dan 
menghantar 240 mesej; jumlah telah meningkat kepada terima 4,470 mesej dan hantar 5,359 mesej pada tahun 1919 (Colonial Office: CO275/101, 1921).

Teknologi tanpa wayar telah mendatangkan kebaikan kepada media massa apabila berita-berita dapat dihantar melalui wireless. Sebagai contoh, berita yang dihantar dari stesen tanpa wayar di Rugby telah diterima oleh stesen di Pulau Pinang dan berjaya diterbitkan dalam surat khabar (Colonial Office: CO275/117, 1928). Selain itu, stesen tanpa wayar di Paya Lebar menyediakan perkhidmatan kepada kapal-kapal untuk penghantaran mesej serta menyediakan perkhidmatan kepada Sarawak dan Christmas Island. Stesen ini juga berperanan untuk menyediakan perkhidmatan kecemasan sekiranya talian telegraf di Kuala Lumpur dan Penaga menghadapi kerosakan. Kedua-dua stesen ini juga menyediakan perkhidmatan tanpa wayar kepada kapal terbang terutamanya Penaga yang banyak menyediakan perkhidmatan tanpa wayar kepada kapal terbang yang melalui kawasan udara bahagian utara Tanah Melayu. Kebiasaannya kapal terbang juga membawa banyak maklumat penting yang perlu disebarkan kepada pentadbiran kolonial di Negeri-Negeri Selat (Colonial Office: CO275/131, 1933).

Sistem tanpa wayar telah memainkan peranan penting dalam penghantaran mesej bagi dua destinasi jarak jauh seperti dengan Sarawak dan Christmas Island. Kedua-dua Sarawak dan Christmas Island juga merupakan koloni British di rantau ini yang memerlukan pemantauan daripada pegawai-pegawai British di Negeri-Negeri Selat. Lingkungan tanpa wayar adalah lebih luas berbanding dengan telegraf dan telefon yang disambung melalui talian. Selain itu, peralatan tanpa wayar juga sering dinaik taraf untuk memastikan proses penghantaran mesej tidak terganggu (Colonial Office: CO273/531/286, 1925). Berbanding dengan telefon, tanpa wayar lebih banyak digunakan oleh para pegawai, pentadbir dan pedagang daripada masyarakat awam. Hal ini kerana tanpa wayar diperkenalkan pada asalnya atas permintaan para pedagang yang ingin berkomunikasi dengan kapal dagang dan seterusnya pihak pentadbiran memerlukannya untuk menerima mesej yang dibawa dari luar. Sehubungan itu, stesen tanpa wayar hanya kekal dua buah sehingga hujung tahun 1930-an. Pembangunan lebih berfokus kepada perkhidmatan lain yang digunakan oleh khalayak ramai.

\section{KESIMPULAN}

Perkhidmatan telefon dan telegraf merupakan salah satu peninggalan kolonial British yang amat penting dan dikekalkan sehingga kini. Kemasukan dan campur tangan British ke atas pentadbiran negeri-negeri di Tanah Melayu telah membawa kepada perkembangan perkhidmatan teknologi komunikasi di seluruh Tanah Melayu terutamanya Negeri-Negeri Selat yang merupakan tumpuan dan pusat pentadbiran utama kolonial British di Tanah Melayu. Sistem pentadbiran yang diperkenalkan oleh British iaitu Negeri-Negeri Selat, NegeriNegeri Melayu Bersekutu dan Negeri-Negeri Melayu Tidak Bersekutu telah ditempatkan Residen, Penasihat British dan Setiausaha Koloni untuk mengurus tadbir sistem pentadbiran, hal-ehwal ekonomi dan pembangunan sosial di setiap negeri. Seorang Gabenor yang merupakan pentadbir tertinggi bagi kolonial British telah ditempatkan di Singapura sebagai pusat pentadbiran Negeri-Negeri Selat. Oleh itu, sistem komunikasi memainkan peranan penting sebagai alat dan medium untuk penghantaran maklumat. Sehubungan itu, wujud inisiatif pentadbiran British untuk mengembangkan sistem komunikasi di Negeri-Negeri Selat supaya proses penyampaian maklumat dan aktiviti komunikasi dapat dilakukan dengan lebih efektif. 
Secara keseluruhan, pentadbiran British telah memainkan peranan yang sangat penting dalam membangunkan sistem komunikasi di Negeri-Negeri Selat pada era kolonial. Antara tahun 1902 hingga 1938, banyak sumbangan telah diberikan oleh British melalui Jabatan Pos dan Telegraf Negeri-Negeri Selat kepada sistem pentadbiran, sosial dan ekonomi di Negeri-Negeri Selat. Antara sumbangannya ialah pembangunan sosial dan pentadbiran melalui teknologi moden. Salah satu usaha yang paling kerap dilakukan oleh British adalah dalam pemasangan talian-talian telegraf dan telefon di seluruh Negeri-Negeri Selat. Untuk memudahkan komunikasi menggunakan telegraf dan telefon, talian telefon dan telegraf telah ditambah untuk menghubungkan ketiga-tiga buah negeri dari utara ke selatan. Hal ini membolehkan segala maklumat penting dapat disampaikan kepada Gabenor di Singapura melalui telegram dan panggilan telefon. Selain itu, talian ini juga menghubungkan NegeriNegeri Melayu yang lain seperti Perak, Selangor, Negeri Sembilan dan Johor. Penduduk di negeri-negeri ini juga dapat menikmati perkhidmatan ini selain memudahkan urusan pentadbiran di negeri-negeri tersebut. Pada masa yang sama, bangunan penting seperti hospital juga dipasang talian telefon dan perkara ini merupakan salah satu sumbangan kepada kebajikan dan kesihatan penduduk. British juga sering membawa masuk talian-talian baharu dan berkualiti untuk dipasang di Negeri-Negeri Selat bagi menggantikan talian lama untuk menyediakan perkhidmatan yang lebih baik kepada para penduduk dan juga pentadbiran kolonial. Talian baharu boleh menampung penggunaan yang lebih ramai. Stesen pertukaran juga dinaik taraf dengan sistem baharu untuk memudahkan proses pertukaran talian telefon. Hal ini telah membawa evolusi teknologi komunikasi di Negeri-Negeri Selat dalam membantu pelancaran urusan pentadbiran British di seluruh Tanah Melayu terutamanya Negeri-Negeri Selat dan negeri-negeri koloni yang lain. Peningkatan kualiti telefon dan telegraf juga membawa manfaat kepada masyarakat awam di seluruh Negeri-Negeri Selat kerana semua lapisan masyarakat berpeluang untuk menikmati perkhidmatan komunikasi yang disediakan oleh pentadbiran British.

Kajian ini telah menekankan perkembangan teknologi komunikasi di Negeri-Negeri Selat dan sumbangannya ke atas pentadbiran British, sosial dan ekonomi pada tahun 1902 hingga tahun 1938 iaitu sebelum Perang Dunia Kedua. Teknologi komunikasi di Tanah Melayu terus berkembang selepas Perang Dunia Kedua. Selepas peperangan, teknologi ini terus berkembang sehingga ke hari ini dengan melalui beberapa fasa mengikut perkembangan teknologi komunikasi secara global. Akhir kata, perkhidmatan komunikasi di Negeri-Negeri Selat merupakan perkara yang sangat penting sebagai asas perkembangan sistem komunikasi di Malaysia pada hari ini. Perubahan yang dibawa oleh pentadbiran British di Negeri-Negeri Selat merupakan sesuatu yang sangat penting dan memberi sumbangan besar dalam menyediakan teknologi komunikasi. Sumbangan ini dapat dirasai sehingga ke hari ini. Banyak manfaat yang dapat kita nikmati pada hari ini dan telefon telah menjadi alat komunikasi yang tidak dapat berpisah dengan kehidupan seharian manusia. Teknologi komunikasi juga berkembang dengan adanya talian internet yang menghubungkan seluruh dunia. 


\section{BIODATA}

Koh Kuan Wei merupakan graduan Sarjana Sastera (Sejarah Malaysia), Fakulti Sains Sosial dan Kemanusiaan, Universiti Kebangsaan Malaysia dan kini berkhidmat sebagai Eksekutif Halehwal Akademik di Xiamen University Malaysia, Sepang. E-mel: kuanwei.koh@xmu.edu.my

Zubaidah V. P. Hamzah merupakan Pensyarah Kanan Program Sejarah di Pusat Kajian Sejarah, Politik dan Hal-Ehwal Antarabangsa, Fakulti Sains Sosial dan Kemanusiaan, Universiti Kebangsaan Malaysia. E-mel: zvph@ukm.edu.my

Azlizan Mat Enh merupakan Profesor Madya Program Sejarah di Pusat Kajian Sejarah, Politik dan Hal-Ehwal Antarabangsa, Fakulti Sains Sosial dan Kemanusiaan, Universiti Kebangsaan Malaysia. E-mel: azlizan@ukm.edu.my 


\section{REFERENCES}

Al-Amril Othman, \& Mohd Nor Shahizan Ali. (2018). Misinterpretation of rumors towards racial conflict: A review on the impact of rumors spread during the riot of May 13, 1969. Jurnal Komunikasi: Malaysian Journal of Communication, 34(3), 271-282.

Andaya, B. W. \& Andaya, L. Y. (1982). A history of Malaysia. MacMillan Education Ltd.

Azharudin Mohamed Dali. (2001). Perkembangan sistem telekomunikasi di Selangor: Telegraf dan telefon 1874-1896. Kuala Lumpur: Persatuan Sejarah Malaysia.

Azlizan Mat Enh, \& Norlilawati Samak. (2020). Peranan akhbar sebagai wadah komunikasi pemerintah kepada rakyat selepas Pilihan Raya Umum 1969. Jurnal Komunikasi: Malaysian Journal of Communication, 36(1), 1-19.

Chai, H. C. (1967). The development of British Malaya 1896-1909 (2nd ed.). Oxford University Press.

Colonial Office, CO273/369/10546. (1911, March 7). Wireless telegraph station on Penang Hill [Letter from the Secretaries, Chamber of Commerce, Penang to the Hon'ble the Colonial Secretary, Singapore].

Colonial Office, CO273/375/41617. (1911, December 6). Enquiry with the telephone system.

Colonial Office, CO273/394/28355. (1912, June 4). Report on telegraph and telephone system.

Colonial Office, CO273/413/15783. (1914, April 29). Wireless telegraph stations in Singapore and Penang.

Colonial Office, CO273/531/286. (1925, December 5). Modernization of wireless telegraph station at Selatar.

Colonial Office, CO275/64. (1902). Annual report for the year 1901 [Report of Postal Department by Acting Postmaster - General, S. S.].

Colonial Office, CO275/66. (1903). Postal and Telegraph Department of the Straits Settlements [Annual department reports of the Straits Settlements for the year 1902].

Colonial Office, CO275/68. (1905). Postal and Telegraph Department of the Straits Settlements [Annual departmental reports of the Straits Settlements for the year 1903].

Colonial Office, CO275/70. (1905). Postal and Telegraph Department of the Straits Settlements [Annual departmental reports of the Straits Settlements for the year 1904].

Colonial Office, CO275/74. (1907). Postal and Telegraph Department of the Straits Settlements [Annual department reports of the Straits Settlements for the Year 1906].

Colonial Office, CO275/77. (1908). Postal and Telegraph Department of the Straits Settlements [Annual departmental reports of the Straits Settlements for the year 1907].

Colonial Office, CO275/79. (1910). Postal and Telegraph Department of the Straits Settlements

[Annual departmental reports of the Straits Settlements for the year 1908].

Colonial Office, CO275/81. (1910). Postal and Telegraph Department of the Straits Settlements

[Annual departmental reports of the Straits Settlements for the year 1909].

Colonial Office, CO275/87. (1912). Postal and Telegraph Department of the Straits Settlements

[Annual departmental reports of the Straits Settlements for the year 1911].

Colonial Office, CO275/94. (1915). Postal and Telegraph Department of the Straits Settlements

[Annual departmental reports of the Straits Settlements for the year 1914].

Colonial Office, CO275/96. (1916). Postal and Telegraph Department of the Straits Settlements

[Annual departmental reports of the Straits Settlements for the year 1915].

Colonial Office, CO275/98. (1918). Postal and Telegraph Department of the Straits Settlements

[Annual departmental reports of the Straits Settlements for the year 1916]. 
Colonial Office, CO275/100. (1920). Postal and Telegraph Department of the Straits Settlements [Annual departmental reports of the Straits Settlements for the year 1918].

Colonial Office, CO275/101. (1921). Postal and Telegraph Department of the Straits Settlements [Annual departmental reports of the Straits Settlements for the year 1919].

Colonial Office, CO275/103. (1922). Postal and Telegraphs Department of the Straits Settlements [Annual departmental reports of the Straits Settlements for the year 1920].

Colonial Office, CO275/105. (1923). Postal and Telegraph Department of the Straits Settlements [Annual departmental reports of the Straits Settlements for the year 1921].

Colonial Office, CO275/107. (1924). Postal and Telegraph Department of the Straits Settlements [Annual departmental reports of the Straits Settlements for the year 1922].

Colonial Office, CO275/112. (1926). Postal and Telegraph Department of the Straits Settlements [Annual departmental reports of the Straits Settlements for the year 1924].

Colonial Office, CO275/117. (1928). Postal and Telegraph Department of the Straits Settlements [Annual departmental reports of the Straits Settlements for the year 1926].

Colonial Office, CO275/121. (1929). Postal and Telegraph Department of the Straits Settlements [Annual departmental reports of the Straits Settlements for the year 1928].

Colonial Office, CO275/124. (1930). Posts and Telegraph Department of the Straits Settlements [Annual departmental reports of the Straits Settlements for the year 1929].

Colonial Office, CO275/126. (1932). Postal and Telegraph Department of the Straits Settlements [Annual departmental reports of the Straits Settlements for the year 1930].

Colonial Office, CO275/129. (1933). Report of the Posts and Telegraphs Department for the year 1931 [Annual departmental reports of the Straits Settlements for the year 1931].

Colonial Office, CO275/131. Annual report on the Postal and Telegraph Department for the year 1932 [Annual departmental reports of the Straits Settlements for the year 1932].

Colonial Office, CO275/136. (1936). Annual report on the Posts and Telegraphs Departments of the Malayan Postal Union for the year 1934 [Annual departmental reports of the Straits Settlements for the year 1934].

Drabble, J. H. (2000). An economic history of Malaysia, c. 1800-1900: The transition to modern economic growth. MacMillan Press Ltd.

Jessy, J. S. (1979). Sejarah Tanah Melayu (1400-1959). Dewan Bahasa dan Pustaka.

Kaur, A. (1985). Bridge and barrier: Transport and communications in Colonial Malaya 18701957. Oxford University Press.

Koh, K. W., Zubaidah V. P. Hamzah, \& Azlizan Mat Enh. (2020). Pembangunan perkhidmatan pos dan sumbangannya kepada pentadbiran British dan masyarakat di negeri-negeri Selat 1902-1938. Jurnal Dunia Pengurusan, 2(2), 12-24. 
Muhammad Aslah Akmal Azmi, \& Mohd Samsudin. (2018). Propaganda British di Tanah Melayu pada zaman Perang Dunia Pertama (1914-1916). Jurnal Komunikasi: Malaysian Journal of Communication, 34(4), 19-41.

Syed Arabi Idid. (2019). Communication education in Malaysia: Early days to recent years. Jurnal Komunikasi: Malaysian Journal of Communication, 35(1), 303-318.

Turnbull, C. M. (2009). A history of modern Singapore 1819-2005. Singapore: NUS Press. 